\title{
Mine Pressure Behavior Characteristics and Control Methods of a Reused Entry that Was Formed by Roof Cutting: A Case Study
}

\author{
Yajun Wang $\mathbb{D}^{1,2}$ Haosen Wang, ${ }^{2}$ Manchao He, ${ }^{1,2}$ Qi Wang, ${ }^{2}$ Yafei Qiao, ${ }^{1}$ and Jun Yang $\mathbb{D I}^{2}$ \\ ${ }^{1}$ Department of Geotechnical Engineering, College of Civil Engineering, Tongii University, Shanghai 200092, China \\ ${ }^{2}$ State Key Laboratory for Geomechanics \& Deep Underground Engineering, China University of Mining \& Technology, \\ Beijing 100083, China \\ Correspondence should be addressed to Jun Yang; yj_cumtb@163.com
}

Received 7 July 2019; Revised 23 September 2019; Accepted 16 January 2020; Published 27 February 2020

Academic Editor: Huu-Tai Thai

Copyright (c) 2020 Yajun Wang et al. This is an open access article distributed under the Creative Commons Attribution License, which permits unrestricted use, distribution, and reproduction in any medium, provided the original work is properly cited.

\begin{abstract}
Noncoal pillar mining with automatic formation of a roadway is a new coal mining method that is tailored to improve the coal resource recovery rate and reduce the investment in roadway tunneling. Using this proposed method, a reuse entry is formed by roof cutting instead of tunneling. In this paper, the S1201-II working face of the Ningtiaota Coal Mine was used as a case study. The stress distribution of surrounding rock and the roof deformation characteristics of the reused entry during the mining process of the second working face were studied through FLAC $^{3 \mathrm{D}}$ numerical simulations combined with field measurements. The results indicate that the zone close to the reused entry led to higher stress in advance. If this stress is superimposed with the lateral pressure of the adjacent mined working face, it will be more difficult to maintain the reused entry. In the engineering case study described here, the reused entry created a stress increase zone and a severe deformation zone in the range of $0-80 \mathrm{~m}$ in front of the working face, and its range was approximately $37.5 \%$ larger than an ordinary entry. The stress peak in the stress increase zone increased by approximately $34.7 \%$ over that of an ordinary entry. The maximum amount of deformation within the severe deformation zone increased by $94.4 \%$ over that of an ordinary entry. To properly control the surrounding rock stress and deformation of the reused entry, a dynamic pressure bearing support in front of the working face with adaptability to the large roof deformation and high support strength is proposed here. Field application results showed that the final roof deformation with the dynamic pressure bearing support can be satisfactorily controlled within $110 \sim 130 \mathrm{~mm}$. These findings can provide a reference for researchers and field engineering technicians when engaging in the support work of reused entry.
\end{abstract}

\section{Introduction}

Longwall mining is a mining method that has been widely used around the globe, which has the advantages of safety, high efficiency, and high mechanization $[1,2]$. However, this mining method generally requires two advance tunnels and a coal pillar with a width of 5-30 m reserved between every two working faces [3]. Consequently, this mining method has led to a huge waste of coal resources, which in turn places the sustainable development and utilization of coal resources in an unfavorable position [4]. Moreover, this mining method requires a high degree of work for entry tunneling, resulting in a large investment in tunneling. And many accidents happen because of the stress concentration caused by the coal pillar [5-9]. To avoid this waste of resources and large investment in tunneling as mentioned above, Prof. He Manchao proposed a method involving noncoal pillar mining with the automatic formation of a roadway [10]. This proposed mining method not only addresses the said problems but also substantially improves the surrounding rock stress of the entry and enhances the entry stability and safety $[11,12]$.

However, the proposed technology is also accompanied with problems. For example, certain in-depth studies should be explored as to the stability mechanism of the entry roof formed by roof cutting, the stress distribution characteristics of the surrounding rock, the law of the roof deformation variation, and the appropriate control countermeasures. To date, many findings for these problems have been reported [13-15]. However, the existing research results are all aimed at the stage of retaining roadway. The findings of the 
distribution of the surrounding rock stress, the law of roof deformation variation, and the surrounding rock control method in the second service stage of reused entry have not yet been published.

In this paper, the reused entry of the S1201-II working face of the Ningtiaota Coal Mine in Yulin, Shaanxi, was used as a case study. Surrounding rock stress distribution and roof deformation characteristics in the second service stage of reused entry were investigated through $\mathrm{FLAC}^{3 \mathrm{D}}$ numerical simulation combined with the site measurement. The roof control method that fits the mine pressure behavior of the reused entry was then proposed accordingly. The results of this research can instruct scientific researchers and site engineering technicians to provide site entry support properly and are of great significance in improving the theoretical system and the key technology system of noncoal pillar mining with the automatic formation of a roadway.

\section{Geological Background and Site Details}

Ningtiaota Coal Mine is located in Shenmu county, Shannxi province, China. The S1201-II working face is the test working face for noncoal pillar mining with the automatic formation of a roadway. The tendency length of the test working face is $280 \mathrm{~m}$, and the strike length is $2344 \mathrm{~m}$. Meanwhile, the thickness of the coal seam is 3.81-4.35 m, the average thickness is $4.11 \mathrm{~m}$, and the buried depth is $115 \sim 170 \mathrm{~m}$. The existing conditions of the coal seam are stable, and the coalbed pitch is nearly horizontal. The roadway layout of the working face is shown in Figure 1. In the figure, the headgate of S1201-II is tunneled in advance, while the air return way of S1201-II is formed by noncoal pillar mining with the automatic formation of a roadway, and the entry remained in the mining process of the working face, with a total length of $2344 \mathrm{~m}$. The S12013 working face is the next working face adjacent to the S1201-II working face. The tendency length of the S12013 working face is $333 \mathrm{~m}$, and the strike length is $1782 \mathrm{~m}$. The thickness of the coal seam is $3.80-4.21 \mathrm{~m}$, the average thickness is $3.95 \mathrm{~m}$, and the buried depth is $114 \sim 172 \mathrm{~m}$. The mining process of the S12013 working face commenced only after the mining work of the S1201-II working face. The retained return airway of S1201-II is a reused entry. It was also later used as the return airway for S12013. Obviously, the return airway of S1201-II would be subject to intense mining influence by the mining process of S12013. To ensure the safety of this entry, we had to be clearer about its stress distribution characteristics and roof deformation variation, which is the key point to be discussed in Section 3.

In the mining process of the S1201-II working face, the roof of the reused entry was cut. The cutting depth of the test face is designed as $9.0 \mathrm{~m}$, and the cutting angle is $10^{\circ}$. The roof of the entry is permanently supported using constantresistance and large-deformation anchor cables [16], and the length of the cables is designed as $10.5 \mathrm{~m}, 5$ pieces in a row, and with a row spacing of $0.8 \mathrm{~m}$. Within the range of $0 \sim 160 \mathrm{~m}$ behind the working face, a temporary support depending on a row of gangue supports that are arranged on the goaf side is provided. The working resistance of one support is $4000 \mathrm{kN}$, and the distance from the centers to the adjacent supports is $2400 \mathrm{~mm}$; when the surrounding rock of the roadway tends to be stable, these supports are gradually removed. The specific support parameters are shown in Figure 2.

\section{Dramatic Effect of Roof Structure on a Reused Entry}

3.1. Structural Characteristic of the Main Roof. For the longwall mining method, the main roof in goaf gradually exhibits the suspension state of a "fixed support in four sides" as the first working face is mined forward [17]. When the working face is mined to the critical distance, the main roof is subject to "O-X" type failure and forms fractured rocks $A, B$, and $C$ [18]. Later, the main roof regularly cycles in the form of semi- “O-X" type failure and forms fractured rocks, resulting in a significant stress concentration in the coal body $[19,20]$, as shown in Figure 3(a). To date, many research studies have studied the deformation characteristics, stress distribution, and control countermeasures of the reused entry during the mining process of the first working face $[14,21]$, so these will not be further described here. This work mainly aimed at observing the stress distribution and deformation characteristics of the reused entry during the mining process of the second working face. As the second working face was mined forward, the main roof in goaf exhibited the state of "fixed support at three sides and simple support at one side" [22]. According to existing studies, the main roof under this state would be subject to "O-Y" type failure, which then forms D and E. Later, the main roof regularly cycled in the form of semi-"O-Y" type failure and continuously formed new fractured rocks, as shown in Figure 3(b).

The main roof behind the working face was continuously fractured and caused rotating and sinking during the mining process of the second working face [23]. Thus, there was always a stress concentration phenomenon in the coal body in front of the working face [24], and the position of the stress concentration zone continuously moved forward as the working face was mined [25]. According to existing studies, the mine pressure behavior in the middle part of the working face was very obvious during the mining process of the ordinary longwall face [26], but a triangular fractured rock was formed at both ends of the working face. Under the protection of the triangular fractured rock, the mine pressure behavior was not obvious. However, for the second working face, as shown in Figure 3, the main roof in goaf was in "O-Y" type failure and there was a triangular fractured rock $\mathrm{E}$ at the right side of the working face. In this sense, the mine pressure behavior below $\mathrm{E}$ was not obvious and the stress concentration in front of the working face was relatively weak. However, the left side of the working face was immediately adjacent to the goaf on the first working face and the triangular fractured rock disappeared. This would subject the zone close to the reused entry to intense mine pressure behavior just at the middle part of the working face, resulting in a very significant stress concentration near the entry in front of the working face, which may affect the stability of the entry [27]. This will make it extremely difficult 


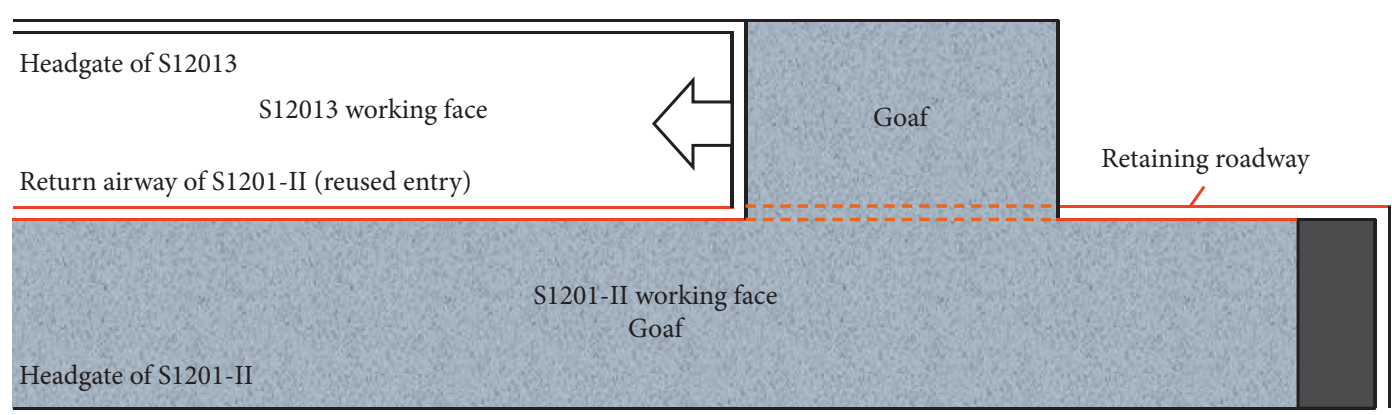

FIgURE 1: Roadway layout of the test working face.

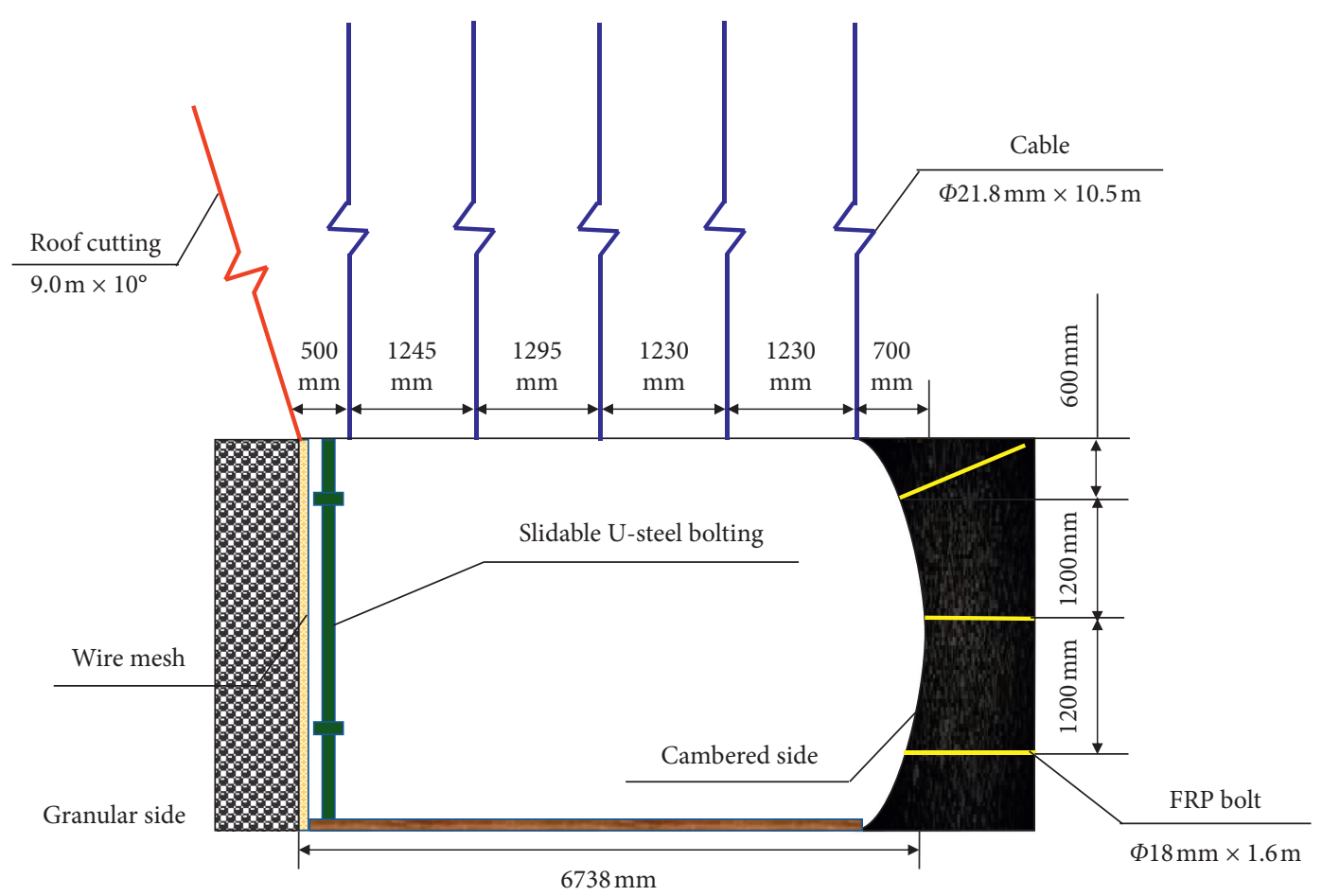

Figure 2: Cross-section diagram of the roadway.

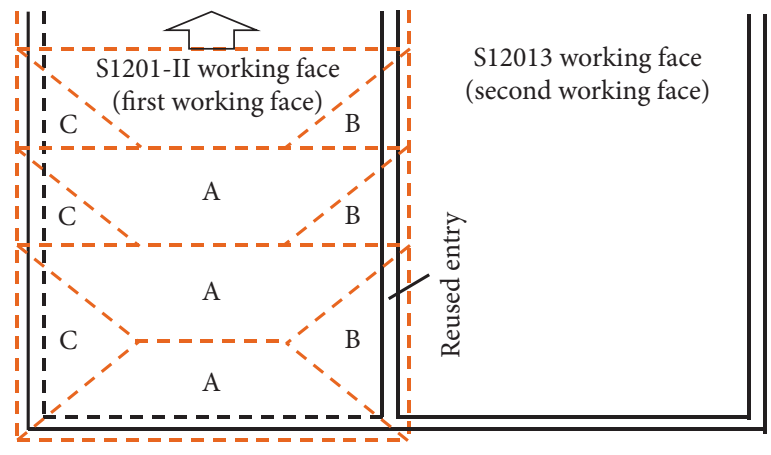

(a)

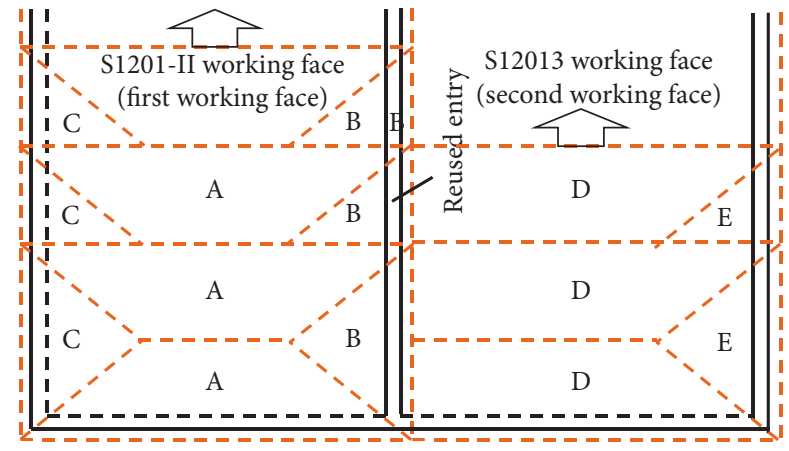

(b)

Figure 3: Plan view of the roof structure: (a) the first working face and (b) the second working face.

to maintain the reused entry during the mining process of the working face. Next, several representative hydraulic supports at both ends of the working face and in the middle part of the working face were illustrated. These site- monitoring data are the most appropriate for verifying the abovementioned results.

The dip length of the S12013 working face was $333 \mathrm{~m}$, and 195 hydraulic supports were arranged; each has a 
working resistance of $10,000 \mathrm{kN}$. The monitoring results of the pressure of two hydraulic supports on both sides of the working face and two hydraulic supports in the middle part of the working face were selected, respectively, for analysis. Of these, \#4 and \#10 were located at the side of the headgate of S12013, approximately $7.0 \mathrm{~m}$ and $17.5 \mathrm{~m}$ from the end of the working face on this side, respectively. Supports \#185 and $\# 191$ were located at the side near the reused entry, approximately $7.5 \mathrm{~m}$ and $7.0 \mathrm{~m}$ from the end of the working face on this side, respectively. The monitoring results of the pressure of 6 hydraulic supports are shown in Figure 4.

According to the monitoring results shown in Figures 4(a) and 4(b), at the side closest to the headgate of S12013, the pressure of \#4 and \#10 always remained at approximately $30 \mathrm{MPa}$ during the period of the working face weighting. This finding verified that the triangular fractured rock E at the right side of S12013, as shown in Figure 3(b), would protect the coal mass body beneath it to some extent. With this protection, the increase in the support pressure below rock $\mathrm{E}$ was not obvious during the working face weighting. According to the monitoring results, as shown in Figures $4(\mathrm{c})$ and $4(\mathrm{~d})$, when the working face tunneled to approximately $70 \mathrm{~m}$, the roof was subject to first weighting. The pressure of \#94 and \#100 located in the middle part of the working face obviously increased, increasing from approximately $30 \mathrm{MPa}$ to approximately $40 \mathrm{MPa}$. After the first weighting, the roof produced a periodic weighing every $15-20 \mathrm{~m}$ with the support pressure at the weighting being generally approximately $40 \mathrm{MPa}$. As a result, under normal circumstances, the mine pressure behavior of the supports in the middle part of the working face was more obvious, which is consistent with many research conclusions [28]. According to the monitoring results, as shown in Figures 4(e) and 4(f), the variation of the pressure of supports on the working face at the side closest to the reused entry was more similar to that in the middle part of the working face. When the roof of the working face was subject to first weighting, the pressure of \#85 and \#191 close to the side of the reused entry obviously increased, changing from approximately $30 \mathrm{MPa}$ to approximately $40 \mathrm{MPa}$. After the first weighting, the roof of the working face would continuously produce a regular periodic weighting with the pressure of the supports at the weighting being generally approximately $40 \mathrm{MPa}$. These findings demonstrated the "O$\mathrm{Y}$ " type fracture and movement characteristics of the main roof of S12013 to a certain extent. Under this influence, within a certain range near the working face, the reused entry would be subject to the intense advance mining influence of the working face and the degree of entry deformation may be more obvious than at the other side of the working face.

3.2. Stress Superposition Effect. According to the abovementioned analysis of the roof structure and movement process, after the mining of the first working face, the pressure of the overlying strata would be transmitted into the coal body on the second working face after the goaf-side roof was damaged, resulting in an extremely high concentrated stress in the surrounding rock near the reused entry. In the mining process of the second working face, the coal body in front of the working face will also cause advance concentrated stress [11]. When the advance mining influence of the working face was superimposed with the lateral concentrated stress generated by the previous working face [29], the concentrated stress peak within a certain range of the surrounding rock in front of the working face would reach a higher level. To grasp the extent and degree of influence of the two superimposed stresses, the superimposition effect of these two types of stress was examined with FLAC3D numerical simulation software.

3.2.1. Numerical Calculation Model. The model dimension is designed as $702 \times 500 \times 200 \mathrm{~m}$, the lower boundary is vertically fixed, and the front, rear, left, and right boundaries are horizontally fixed. The lengths of the S1201-II and S12013 working faces are $280 \mathrm{~m}$ and $333 \mathrm{~m}$, respectively. The thickness of the coal seam is $4.0 \mathrm{~m}$, and the size of the roadway is $6.0 \times 4.0 \mathrm{~m}$. The immediate roof is siltstone with a thickness of $2.0 \mathrm{~m}$, and the main roof is medium sandstone with a thickness of $14.0 \mathrm{~m}$. The floor from top to bottom is siltstone, $10.0 \mathrm{~m}$ thick, and fine sandstone, $15.0 \mathrm{~m}$ thick. The calculation model is established using FLAC3D numerical simulation software, as shown in Figure 5.

In simulation, the Mohr-Coulomb constitutive model is applied to describe the rock strata behaviors. According to the test results of the physical and mechanical properties of the geotechnical drilling core on the test face (No. 185 Team of Shaanxi Coalfield Geology Bureau, 2008), the physicomechanical parameters of the roof and floor rocks are given in Table 1.

3.2.2. Analysis of Simulation Results. To reduce the influence of boundary conditions on the simulation results, the boundary pillars $40 \mathrm{~m}$ away from the rear of the working face were retained without mining and the forward mining process was initiated from $y=40 \mathrm{~m}$ of the working face. When $S 12013$ was tunneled to $160 \mathrm{~m}, 210 \mathrm{~m}$, and $260 \mathrm{~m}$, the vertical stress at the interface between the coal seam and the roof was generated, from which the stress field distribution, as shown in Figure 6, can be obtained.

As it is shown from the simulation results in Figure 6, when the working face was mined to $160 \mathrm{~m}, 210 \mathrm{~m}$, or $260 \mathrm{~m}$, there was always an obvious stress concentration zone at the angle position between S1201-II and S12013, namely, near the working face end close to the reused entry. In the mining direction, this zone was approximately $30 \mathrm{~m}$ long; in the direction of the working face length, it was approximately $25 \mathrm{~m}$ long. The stress concentration peak was approximately $10 \mathrm{~m}$ from the reused entry and the coal wall of the working face. As analyzed earlier, this stress concentration zone was formed as a result of the superimposition of the lateral pressure on the previous working face and the advance mining pressure on the current working face, so it inevitably occurred. It can be clearly seen in Figure 7, that I is the goafside lateral pressure influence zone on the previous adjacent working face, and II is the advance mining pressure 

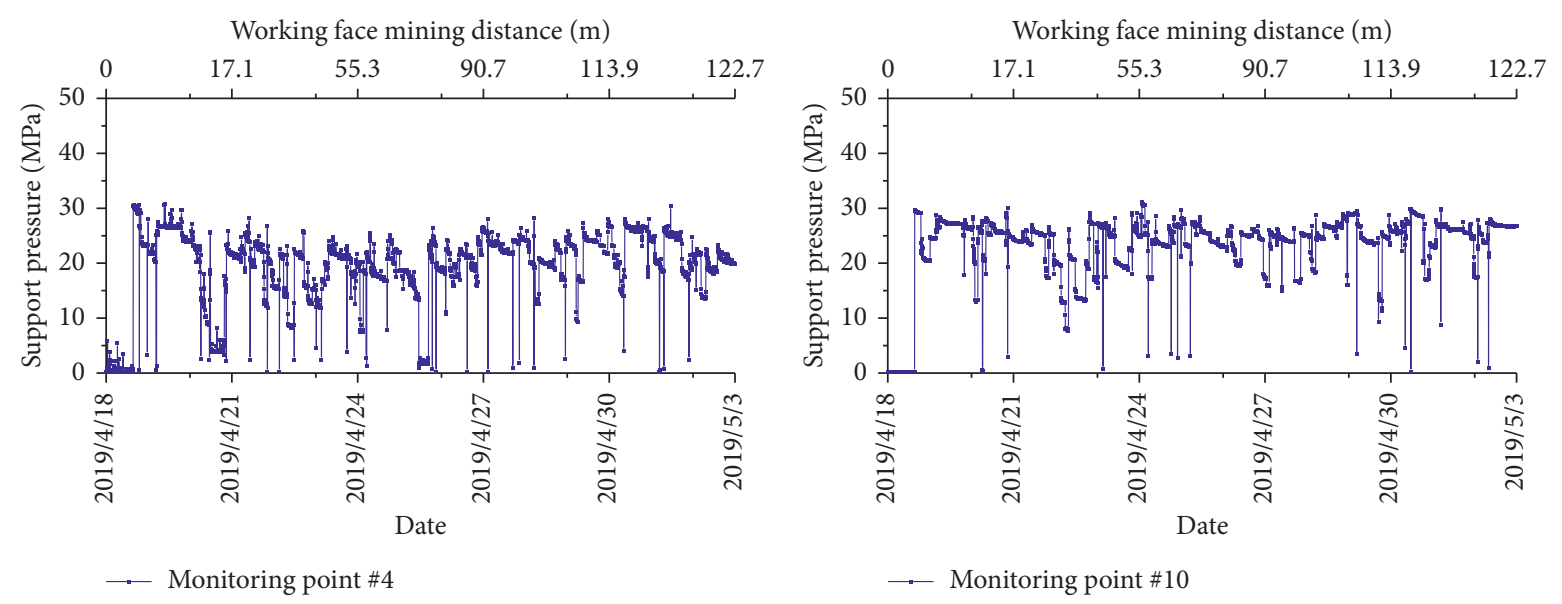

(a)
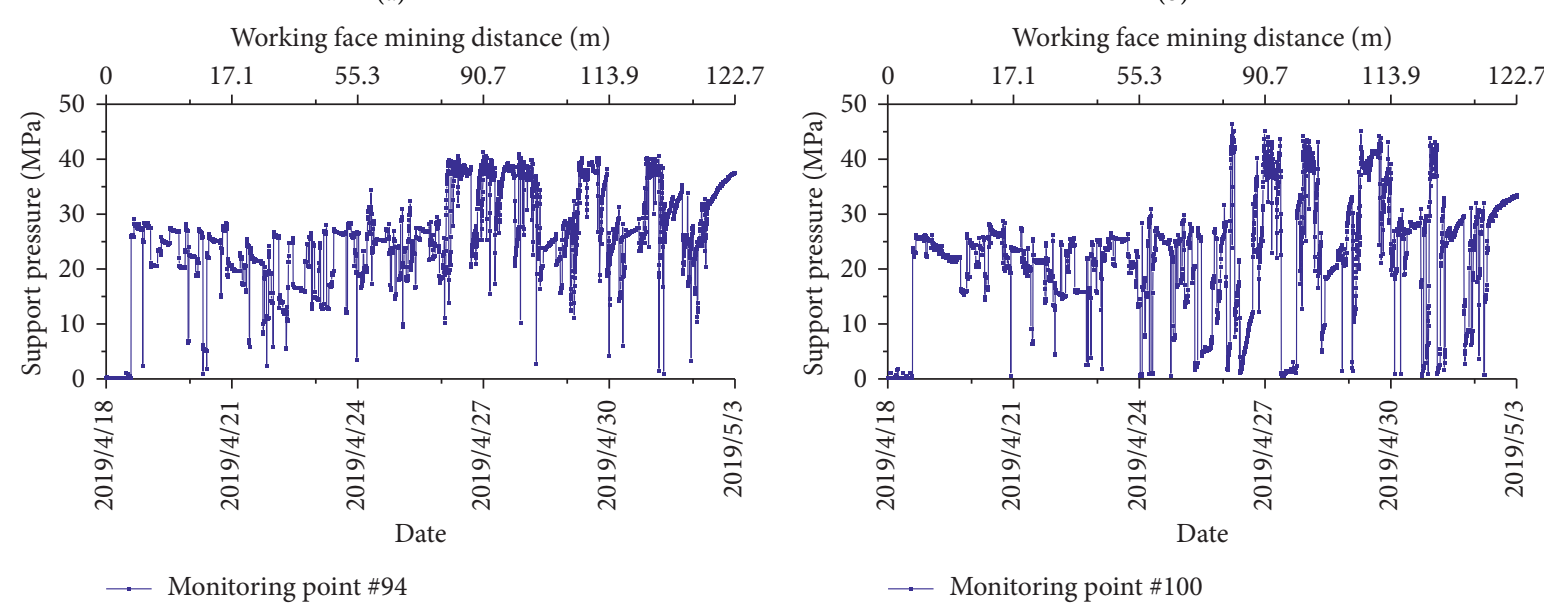

(c)
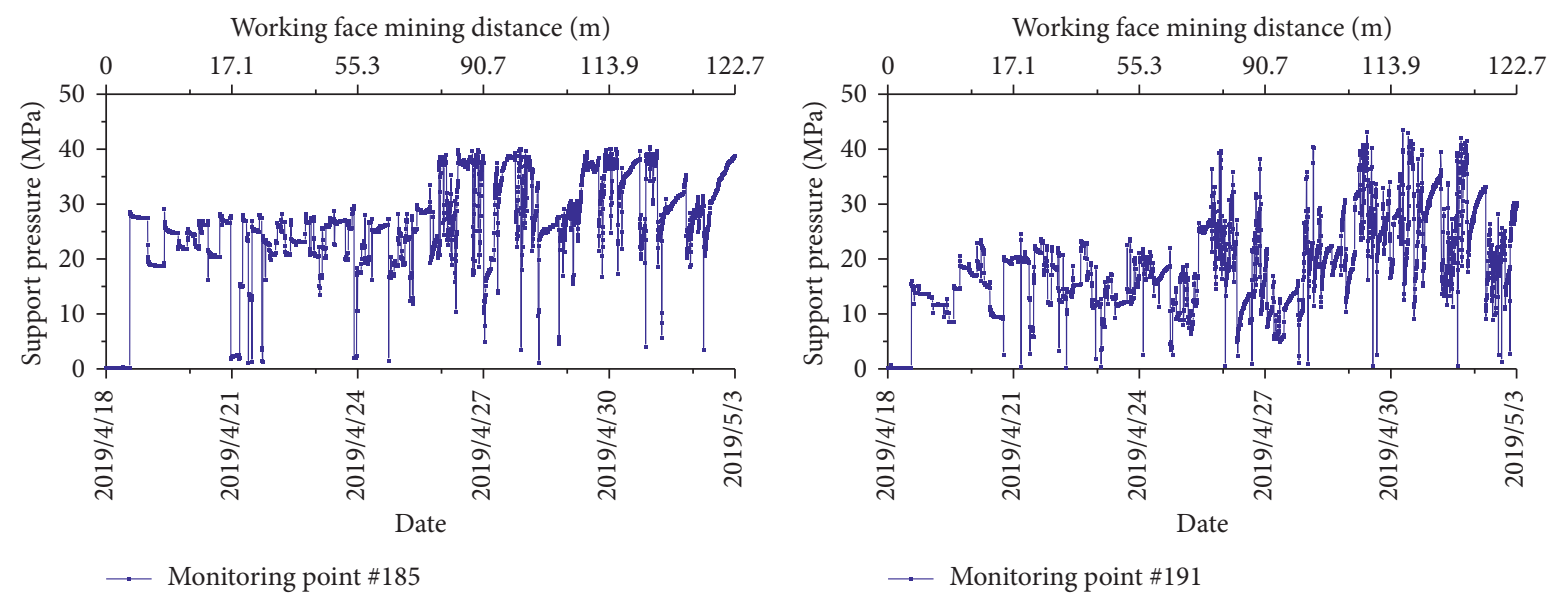

(e)

(f)

FIgURE 4: Working face support pressure curves monitoring point of (a) \#4, (b) \#10, (c) \#94, (d) \#100, (e) \#185, and (f) \#191.

influence zone on the working face. At the intersection of the two zones, the stresses in the goaf-side lateral pressure influence zone and the advance mining pressure influence zone overlapped to form the superimposition influence zone. There was an extremely high-concentrated stress in this zone, which is likely to cause large deformation, collapse, rock burst, coal and gas outburst, and other disasters
$[30,31]$. Therefore, during the second use of the reused entry, we should focus on how to properly provide support in this zone. In Section 4, we specifically analyzed the stress distribution and deformation characteristics around the reused entry in order to identify the appropriate control timing and control range, and we provide a reference for the design of the entry support. 


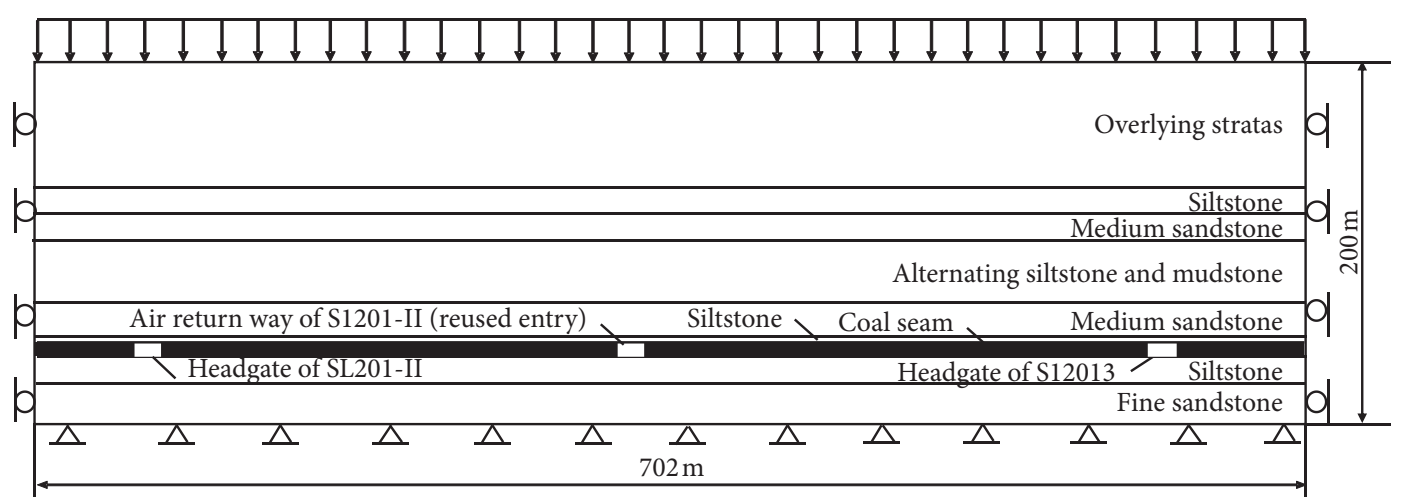

FIGURE 5: Numerical calculation model.

TABle 1: Physicomechanical parameters of rock strata.

\begin{tabular}{|c|c|c|c|c|c|c|c|}
\hline Name of stratum & $\begin{array}{l}\text { Height D } \\
(\mathrm{m})\end{array}$ & $\begin{array}{l}\text { Bulk modulus } \mathrm{K} \\
(\mathrm{GPa})\end{array}$ & $\begin{array}{c}\text { Shear modulus } \\
\mathrm{G}(\mathrm{GPa})\end{array}$ & $\begin{array}{c}\text { Tensile strength } \\
\mathrm{T}(\mathrm{MPa})\end{array}$ & $\begin{array}{c}\text { Cohesion } \mathrm{c} \\
(\mathrm{MPa})\end{array}$ & $\begin{array}{c}\text { Internal friction } \\
\text { angle } \varphi\left(\left(^{\circ}\right)\right.\end{array}$ & $\begin{array}{c}\text { Density } \rho \\
\left(\mathrm{kg} / \mathrm{m}^{3}\right)\end{array}$ \\
\hline Overlying strata & 100 & 7.02 & 4.63 & 0.64 & 1.27 & 40.91 & 2310 \\
\hline Siltstone & 10 & 4.51 & 3.11 & 0.48 & 0.85 & 39.69 & 2460 \\
\hline Medium sandstone & 10 & 4.99 & 3.59 & 0.48 & 1.08 & 40.81 & 2320 \\
\hline $\begin{array}{l}\text { Alternating siltstone } \\
\text { and mudstone }\end{array}$ & 30 & 7.61 & 5.48 & 0.62 & 1.44 & 39.21 & 2380 \\
\hline Medium sandstone & 14 & 5.46 & 4.27 & 0.58 & 1.12 & 41.33 & 2280 \\
\hline Siltstone & 2 & 4.81 & 3.92 & 0.39 & 0.92 & 38.45 & 2040 \\
\hline Coal seam & 4 & 3.95 & 3.22 & 0.36 & 0.85 & 39.69 & 1260 \\
\hline Siltstone & 10 & 10.23 & 8.33 & 1.22 & 2.05 & 40.81 & 2410 \\
\hline Fine sandstone & 20 & 3.78 & 3.08 & 0.85 & 1.75 & 38.42 & 2320 \\
\hline
\end{tabular}

\section{Mine Pressure Behavior Characteristics of the Reused Entry}

4.1. Stress Distribution Characteristics. To investigate the stress distribution and variation characteristics of the surrounding rock near the reused entry during the mining process of the second working face, an observation line parallel to the entry was provided at $10 \mathrm{~m}$ near the reused entry on the interface between the coal seam and the roof. As a control group, an observation line was provided in the middle of the working face and at $10 \mathrm{~m}$ near the headgate of S12013, respectively, as shown in Figure 7.

As shown above, monitoring line 1 is located on the side closest to the reused entry, at a distance of $10 \mathrm{~m}$ from the reused entry. Line 4 is located in the middle part of the working face and Line 5 is located on the side closest to the headgate of S12013, at a distance of $10 \mathrm{~m}$ from the headgate of S12013 $10 \mathrm{~m}$. The vertical stress data on each observation line were extracted and the stress curve was plotted to obtain the stress distribution characteristics at different positions in front of the working face, as shown in Figure 8.

The stress distribution characteristic parameters with respect to the three observation lines are given in Table 2. As it is shown in Figure 8 and Table 2, we can obtain the following characteristics: (1) both ends and the middle part of the working face were subject to an advance pressure influence caused by the mining of the working face, resulting in a certain stress increase in front of the working face, thereby forming the stress increase zone. Within the stress increase zone, the stress in front of the working face increased and then decreased with increasing distance from the working face, until it tended toward stability away from the working face. (2) The stress increase zone of the observation line near the reused entry was located approximately $0 \sim 80 \mathrm{~m}$ in front of the working face, which is basically the same as the middle of the working face. The stress increase zone near the headgate of S12013 was located at approximately $0 \sim 50 \mathrm{~m}$ in front of the working face. The range of the former stress increase zone enlarged approximately $60 \%$ over the latter. (3) The stress peak was generally located at $8 \sim 10 \mathrm{~m}$ in front of the working face. The stress peak on the observation line near the reused entry was obviously larger than the stress value in the middle part of the working face and on the side near the headgate of S12013. The stress peak on the observation line near the reused entry increased by $14.1 \%$ over that of the middle part of the working face, and it increased by $34.7 \%$ over that on one side of the headgate of S12013. (4) Stress values at all locations other than the stress increase zone were basically constant. The stress values on the observation line near the reused entry were obviously larger than those in the middle part of the working face and on the side near the headgate of S12013. The stress peak on the observation line near the reused entry increased by $122.4 \%$ over that of the middle part of the working face, and it increased by $91.0 \%$ over that of the side near the headgate of S12013.

According to the abovementioned simulation results, it can be concluded that subject to the superimposition of the 


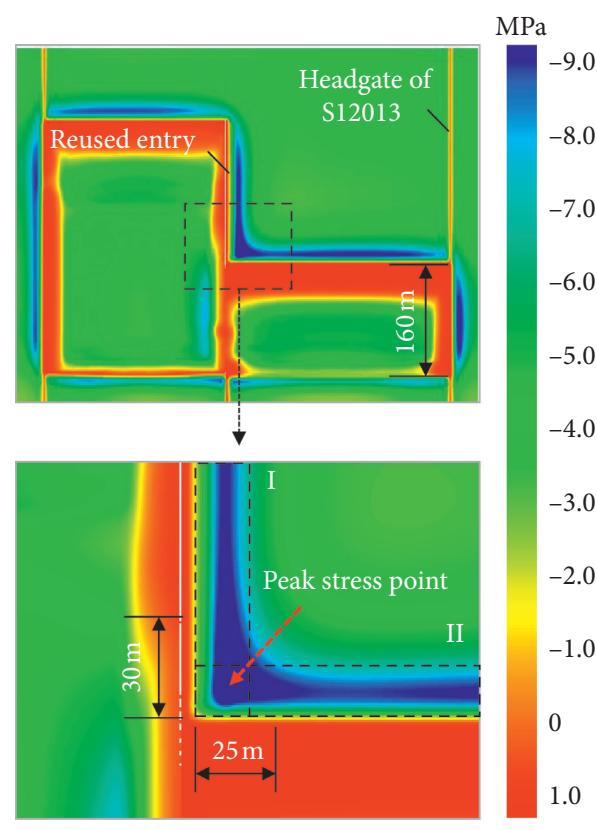

(a)

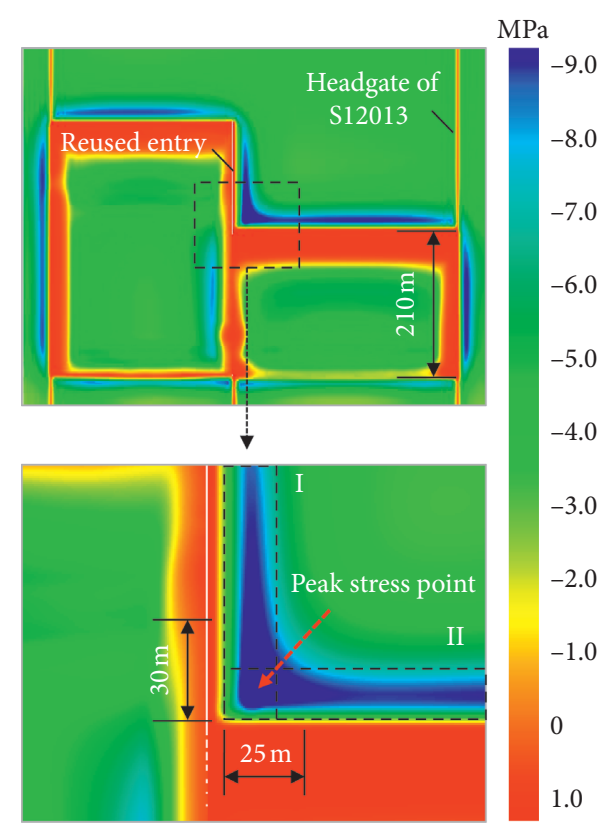

(b)

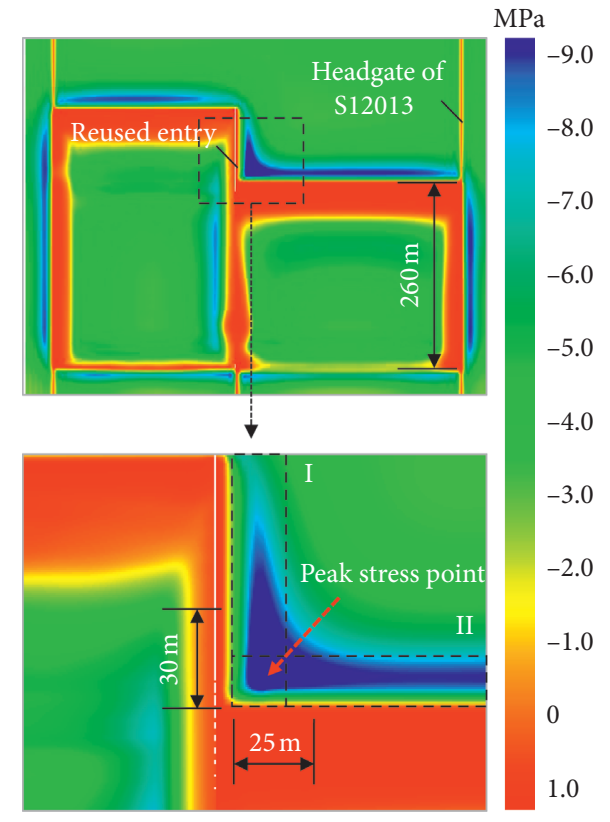

(c)

FIgURE 6: Stress field distribution in the $\mathrm{S} 12013$ working face with advance distance (a) $160 \mathrm{~m}$, (b) $210 \mathrm{~m}$, and (c) $260 \mathrm{~m}$.

lateral pressure of the first working face and the advance mining pressure of the second working face; the stress of the surrounding rock on one side of the reused entry was obviously higher than that in the middle part of the working face and that of the ordinary entry near the end of the other side. Moreover, the range of influence of the advance working face of mining stress near the reused entry was wider than that of the ordinary on the other side.

4.2. Roof Deformation Characteristics. To analyze the roof deformation and variation characteristics of the reused entry during the mining process of the second working face, an observation line parallel to the entry was provided in the middle part of the roof surface of the reused entry. As a control group, an observation line was also provided at exactly the same position as the headgate of S12013, as shown in Figure 9.

As shown above, monitoring lines 1 and 2 were located in the middle part of the reused entry and of the headgate of S12013, respectively. The roof deformation data on two observation lines were extracted and the stress curve was plotted to obtain the displacement characteristics at different positions in front of the working face, as shown in Figure 10. 


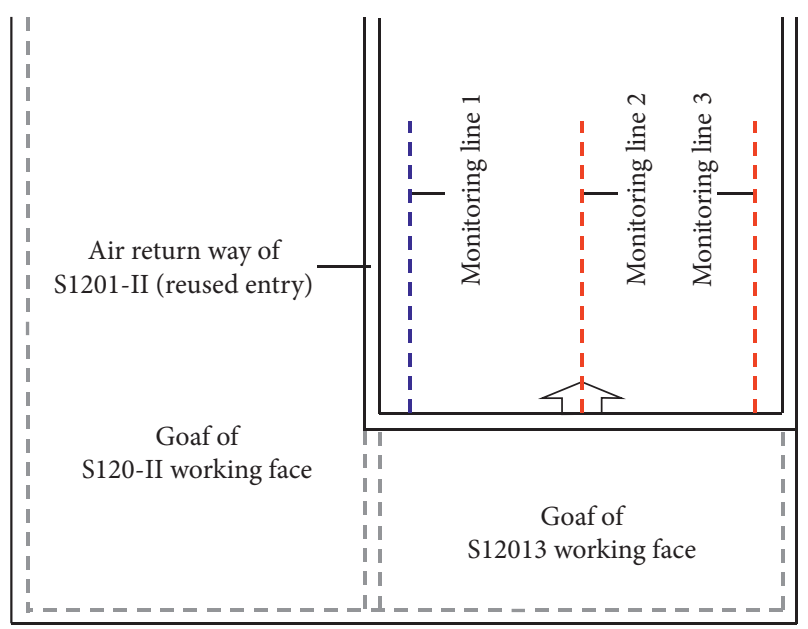

Figure 7: Stress distribution monitoring position in front of the working face.

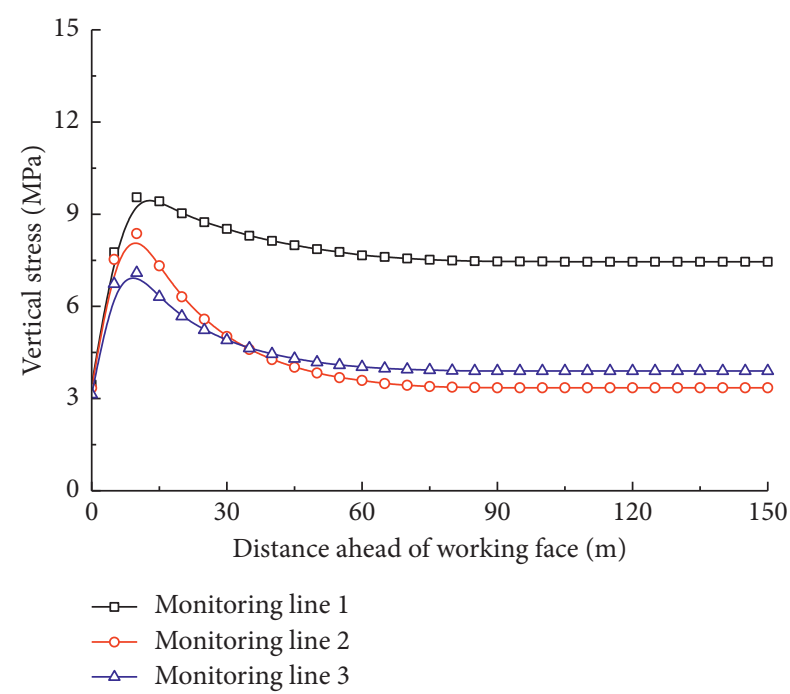

FIGURE 8: Stress distribution curves in front of the working face.

According to Figure 10, we can obtain the following characteristics: (1) whether for the reused entry or the headgate of S12013, the front of the working face would be subject to the advance stress influence caused by mining on the working face, resulting in a rapid increase of roof deformation within a certain range in front of the working face, thereby forming the severe deformation zone. (2) The roof severe deformation zone of the reused entry was located at approximately $0 \sim 80 \mathrm{~m}$ in front of the working face. The roof severe deformation zone of the headgate of $\mathrm{S} 12013$ was located at approximately $0 \sim 50 \mathrm{~m}$ in front of the working face. The range of the former severe deformation zone increased by approximately $60 \%$ over that of the latter. The range of the severe roof deformation zone was exactly consistent with the range of the stress increase area in front of the working face. (3) During the mining process of the second working face, the maximum roof deformation of the headgate of S12013 was $54 \mathrm{~mm}$, the maximum roof deformation of the reused entry was $105 \mathrm{~mm}$, which was increased by $94.4 \%$ over the deformation of the former. The simulation results of the said roof deformation also indicated that, being subject to the superposition effect of the lateral pressure of the first working face and the advance mining pressure of the second working face, the deformation of the reused entry was much larger than that of the headgate of S12013. As a result, in order to improve the stress of surrounding rock and deformation control of the reused entry, provided with the identified influence range of the stress increase zone and the severe deformation zone, an advance support method and associated equipment with adaptability to large roof deformation and high support strength are proposed here. These were tailored not only to reinforce the advance support in this zone but also to ensure the safety of the entry and prevent the support structure from being crushed.

\section{Control Method and Field Test}

5.1. Control Method and Design Parameter. In previous studies, the supplementary support in front of the working face was usually provided by a hydraulic prop or movable advance support. The support force of a hydraulic prop is relatively low, which may meet the requirement of an ordinary entry. However, a hydraulic prop cannot ensure the stability of the reused entry that is substantially subject to the superimposed stresses previously mentioned. Furthermore, we consider that the advance support used in many mines may not also be suitably used for the reused entry. Because the advance support gradually moves forward as a whole, it may provide repeated support for the roof that is likely to damage the roof rock. Moreover, the accessible range of advance support is usually limited to approximately $20 \mathrm{~m}$, failing to meet the requirement for the dynamic influence range of the reused entry (approximately $80 \mathrm{~m}$ ). Therefore, a dynamic pressure bearing support for the advance working face is specifically proposed here, as shown in Figure 11.

The dynamic pressure support of the advance working face is composed of a top beam, stand column, and pedestal. Its functions and characteristics include the following: (1) the support has a high initial supporting force, which provides active support by promptly applying supporting force to the roof, thereby ensuring the integrity of the surrounding rock to the extent possible and making use of its bearing capacity. (2) The support has high working resistance with fast resistance-increasing bearing characteristics. After the roof deformation, the support can provide a bearing effect and reach the designed working resistance within a short time. (3) Subject to the superimposition effect of the lateral pressure of the adjacent working face and the advance dynamic pressure influence of the working face, the roof deformation cannot be completely avoided in most cases. As a result, in order to avoid the support from being damaged, the support has a higher strength and certain contraction in order to adapt to the roof deformation. (4) The support has a small volume, high supporting force, and is easy to transport. As the working face continues to be mined forward, the support near the working face can be directly transported to the forefront of the advance support 
TABLE 2: Stress distribution characteristics in front of the working face.

\begin{tabular}{lccccc}
\hline $\begin{array}{l}\text { Observation } \\
\text { line }\end{array}$ & Observation line position & $\begin{array}{c}\text { Range of stress } \\
\text { increase zone }(\mathrm{m})\end{array}$ & $\begin{array}{c}\text { Stress peak } \\
\text { value }(\mathrm{MPa})\end{array}$ & $\begin{array}{c}\text { Distance from stress peak to } \\
\text { working face }(\mathrm{m})\end{array}$ & $\begin{array}{c}\text { Stress value in the } \\
\text { stability zone }(\mathrm{MPa})\end{array}$ \\
\hline 1 & Near the reused entry & $75 \sim 80$ & 9.55 & 10 & 7.45 \\
\hline 2 & $\begin{array}{c}\text { In the middle part of the } \\
\text { working face }\end{array}$ & $75 \sim 80$ & 8.37 & 10 & 3.35 \\
\hline 3 & $\begin{array}{c}\text { Near the headgate of } \\
\text { S12013 }\end{array}$ & $45 \sim 50$ & 7.09 & 10 & 3.90 \\
\hline
\end{tabular}

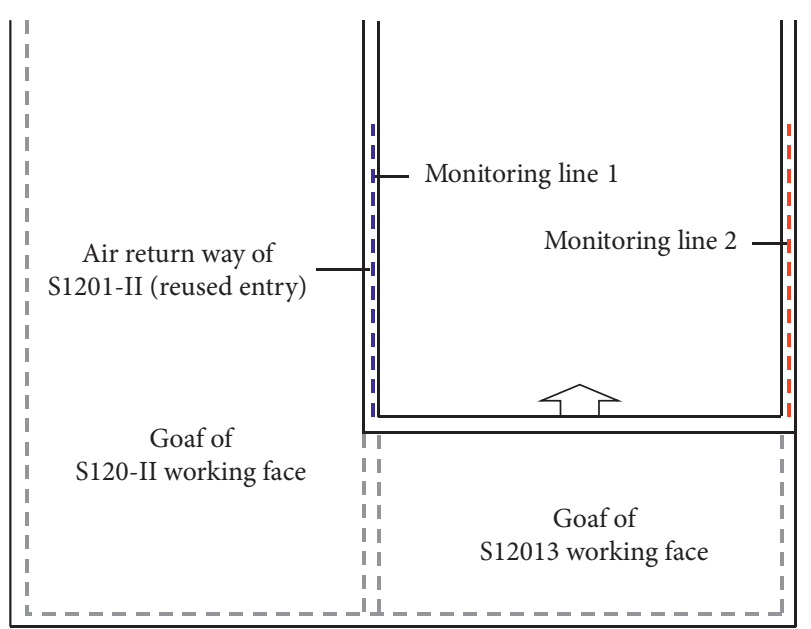

FIGURE 9: Monitoring position of roof deformation in the entry.

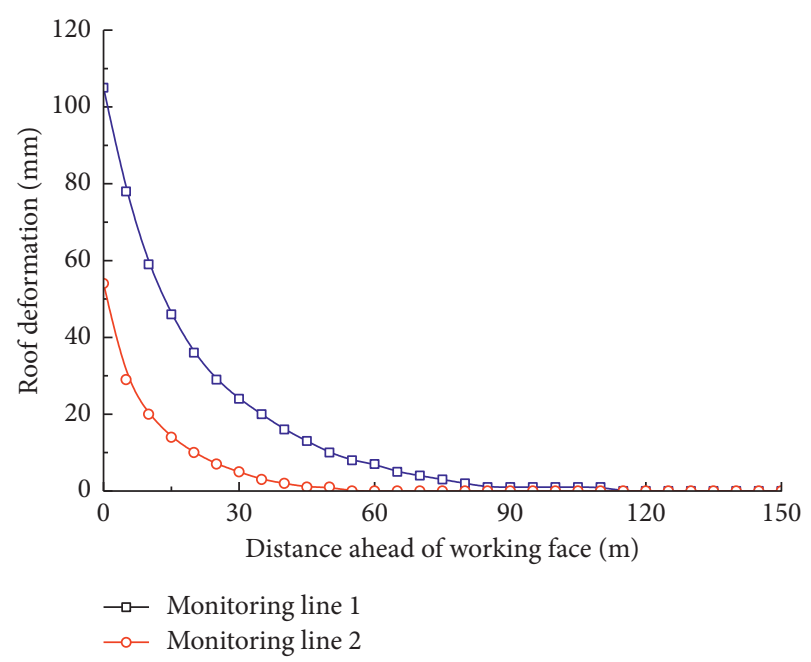

FIgURE 10: Roof deformation distribution curves in front of the working face.

range with a small forklift. In addition, the support range can also be flexibly adjusted according to the actual site needs. This avoids the need for repeated roof supports and inadequate support distance that is caused by conventional advance support.

According to the numerical simulation analysis as described earlier, the range of the severe deformation zone and the stress concentration zone in front of the working face under this experiment is approximately $0 \sim 80 \mathrm{~m}$. For safety concerns in the first experimental trial, the advance support range of this experiment was designed as $100 \mathrm{~m}$. According to the design principle of making the support bearing force larger than the rock weight in the cutting range, the entry size was $6.738 \mathrm{~m}(\mathrm{~L}) \times 8.86 \mathrm{~m}(\mathrm{H})$ and the average bulk density of the roof rock was $26 \mathrm{kN} / \mathrm{m}^{3}$, so the required bearing capacity per unit entry length can be calculated as $1552 \mathrm{kN}$. The supporting force of the support was designed as $4000 \mathrm{kN}$, the support size was designed as $1950 \mathrm{~mm}(\mathrm{~L}) \times 1200 \mathrm{~mm}(\mathrm{~W})$, and the distance on centers between two adjacent supports was $2.4 \mathrm{~m}$, so each section was designed to be supported with two rows of dynamic pressure bearing supports. The supporting force of the support per unit entry length was $3333 \mathrm{kN}$ and the actual safety factor was 2.1 , which can meet the safety requirement. Two rows of dynamic pressure bearing supports were close to the two entry sides and the distance between two rows of supports was not less than $2.5 \mathrm{~m}$, in order to ensure smooth conveyance, as shown in Figure 12.

\subsection{Test Results and Discussion}

5.2.1. Roof-to-Floor Deformation. As the working face was mined, we placed an observation point every $20 \mathrm{~m}$ starting from a distance of $20 \mathrm{~m}$ from the open-off cut to monitor the roof-to-floor deformation. Observations were made at least once a day. The measurement method is manual monitoring, as shown in Figure 13. The first weighting place on the experimental working face was at $70 \mathrm{~m}$. To avoid the influence of the first weighting on the roof deformation, the monitoring results obtained at $200 \mathrm{~m}, 300 \mathrm{~m}, 400 \mathrm{~m}$, and $500 \mathrm{~m}$ from the open-off cut on the working face were selected for analysis. The monitoring curves are shown in Figure 14.

As seen from Figure 14, at all four observation points, the roof-to-floor deformation became larger as the distance from the working face is smaller. Beyond approximately $75 \mathrm{~m}$ in front of the working face, the roof-to-floor deformation of the reused entry was almost 0 , and there was no obvious increase. Meanwhile, according to the site observation, the roof and solid coal body within this range was relatively flat without obvious rib spalling and roof cracking. At approximately $25 \sim 75 \mathrm{~m}$ in front of the working face, the roof-to-floor deformation gradually increased as the distance from the working face was smaller. Obviously, the deformation of the reused entry subject to the advance mining of the working face began to increase from approximately $75 \mathrm{~m}$ in front of the working face, which is consistent with the results of numerical simulation analysis. This also proved that the designed range of the advance support could meet the specified requirement. Within 


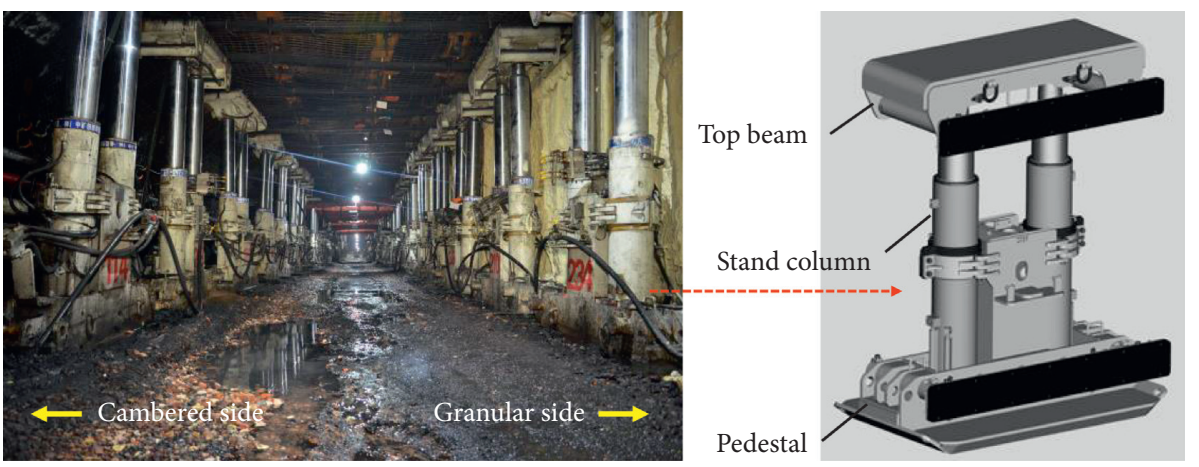

FIGURE 11: Dynamic mining bearing support of the advance working face.

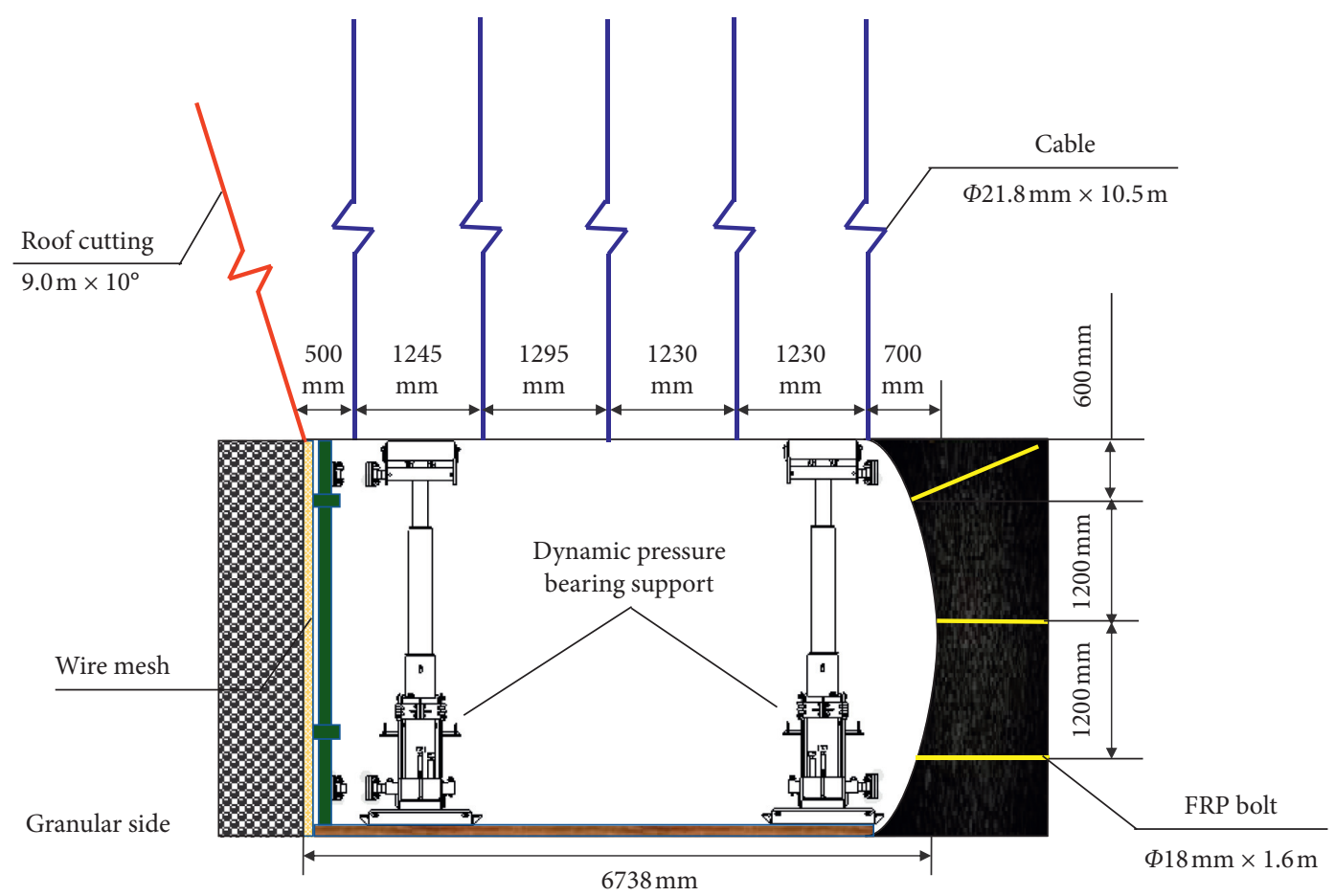

(a)

Cambered side

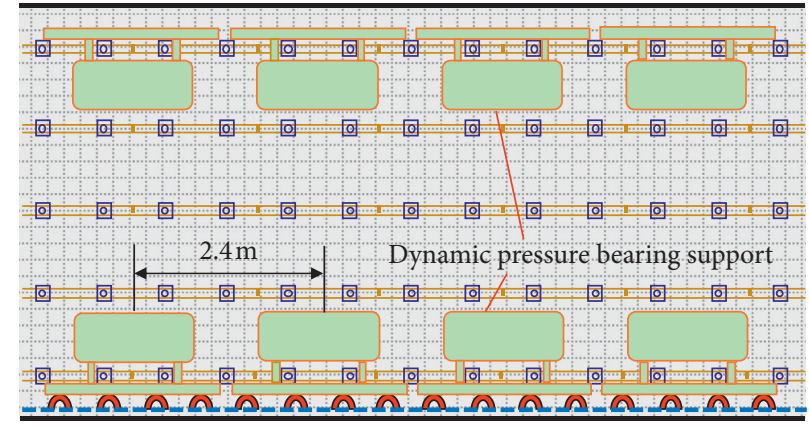

Granular side

(b)

FIGURE 12: Design parameters for the dynamic bearing support in front of the working face: (a) cross-section diagram and (b) plan view. 


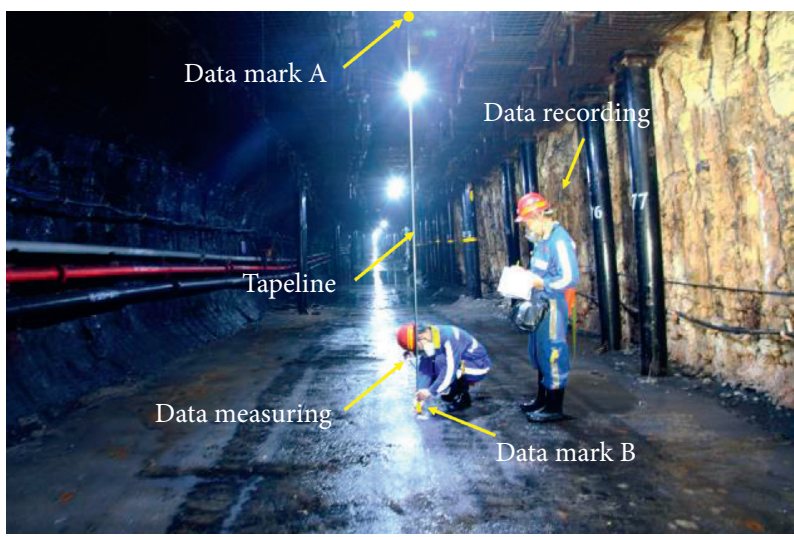

FIGURE 13: Monitoring method of roof-to-floor deformation.

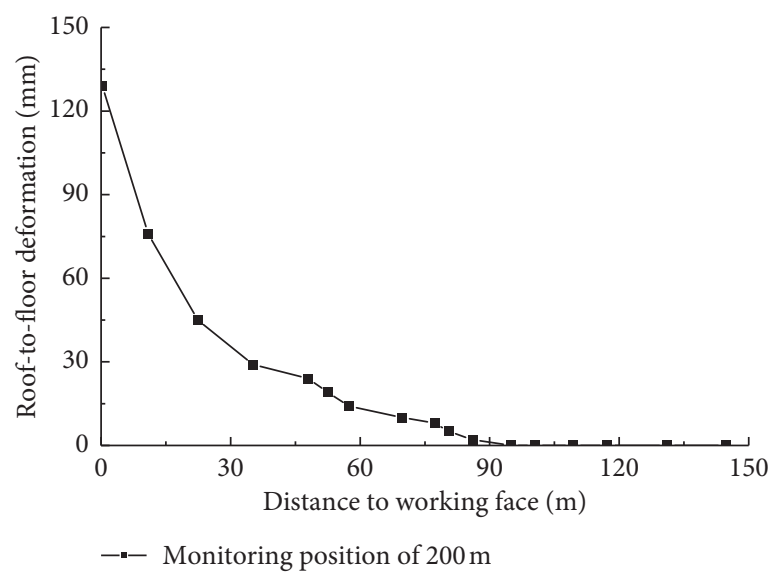

(a)

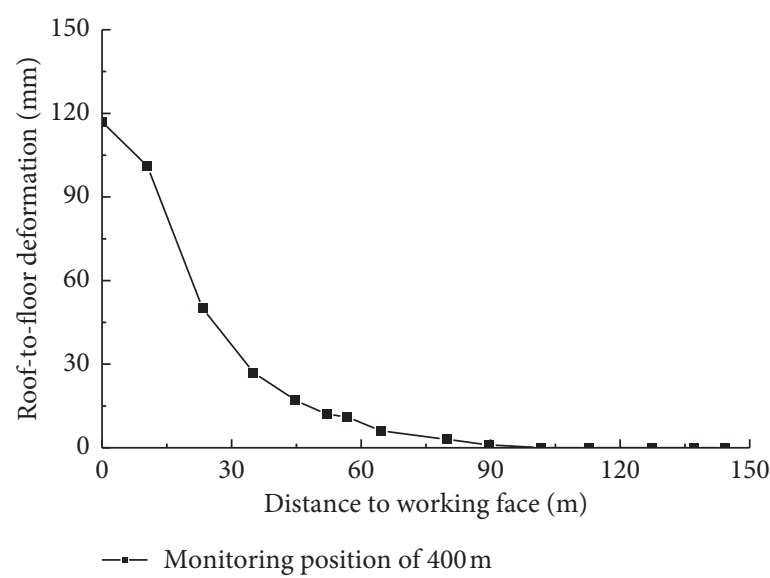

(c)

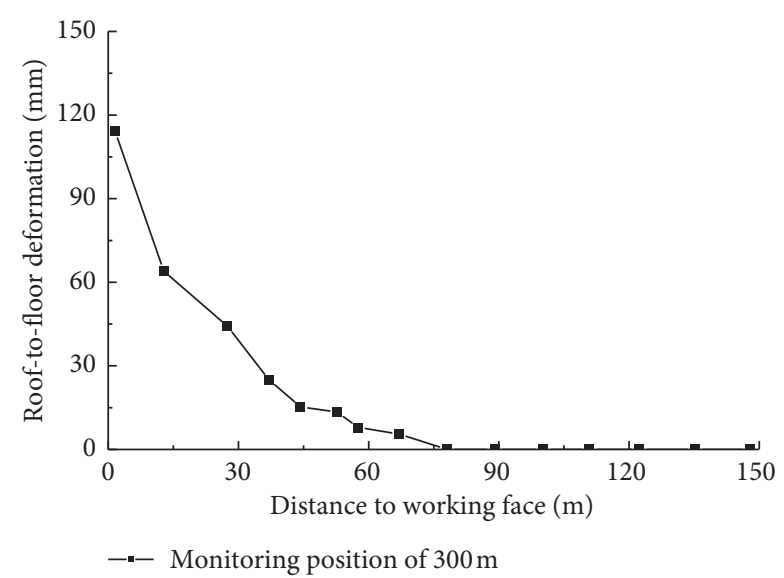

(b)

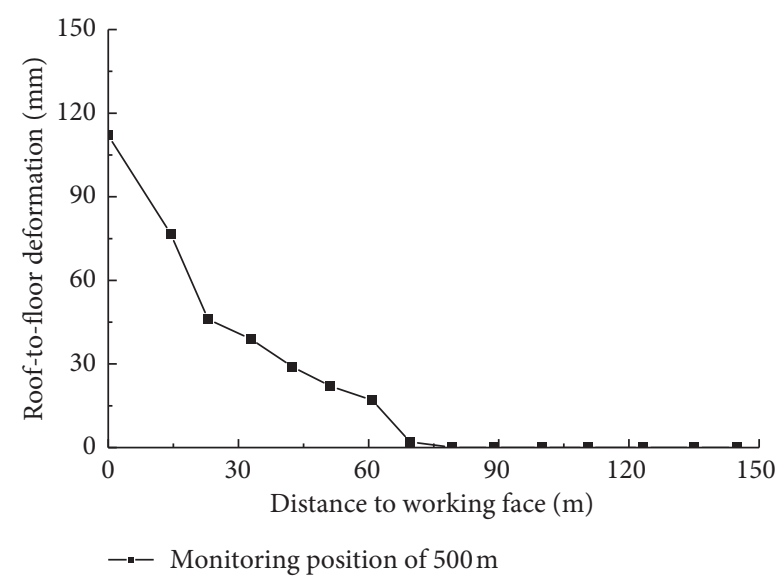

(d)

FIGURE 14: Monitoring results of roof-to-floor deformation.

approximately $0 \sim 25 \mathrm{~m}$ of the front of the working face, the roof deformation in the entry began to increase significantly. This indicated that the zone closer to the working face should be most subject to the superimposition of the advance dynamic pressure influence of the working face and the lateral pressure of the adjacent working face. In this zone, the roof deformation was so severe as to be of likely danger, and particular attention should be paid to roof control. After the use of the dynamic pressure bearing support, the final roof deformation can be controlled up to $110 \sim 130 \mathrm{~mm}$, suggesting a satisfactory control effect.

5.2.2. Dynamic Pressure Bearing Support Force in Front of the Working Face. According to the design scheme, as the working face was mined forward, 80 dynamic pressure bearing supports arranged in two rows were always used to provide advance supplementary support within a range of 

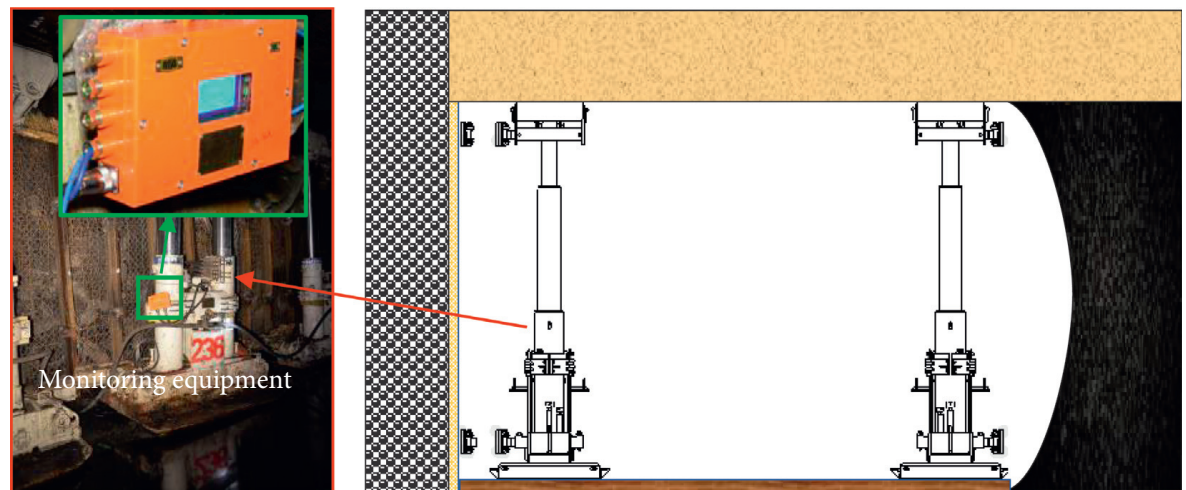

FIGURE 15: Monitoring method of dynamic pressure bearing supports.

approximately $100 \mathrm{~m}$ in front of the working face. We started numbering the supports from the position closest to the working surface. The supports located near the solid coal side were assigned with \#A01 \#A40, in which the support closest to the working face was assigned with \#A01; the supports located near the goaf side were assigned with \#B01 \#B40, in which the support closest to the working face was assigned with \#B01. As the working face was mined forward, the support close to the working face cyclically moved to the forefront. At every $100 \mathrm{~m}$ of mining, the working face was considered a cycle, with all dynamic pressure bearing supports completing a forward movement following a cycle. Since the first cycle would be subject to the first weighting, the pressure monitoring results obtained from four supports (\#A39, \#A4\#, \#B39, and \#B40) in the second cycle were selected for analysis. During the monitoring process, the pressure data was read from the supports once following the completion of a coal cutting (namely, mining forward $0.8 \mathrm{~m}$ ) on the working face. The measurement method and equipment are shown in Figure 15. The plotted monitoring curve is shown in Figure 16.

As it is seen from Figure 16, beyond approximately $75 \mathrm{~m}$ from the front of the working face, the pressure of the dynamic pressure-bearing support did not increase significantly, but basically retained the initial supporting force. At approximately $25 \sim 75 \mathrm{~m}$ from the front of the working face, the pressure of the dynamic pressure bearing support began to gradually increase as the distance from the working face was closer. Within approximately $0 \sim 25 \mathrm{~m}$ of the front of the working face, the pressure of the dynamic pressure bearing support began to increase rapidly. This indicates that when the distance from the working face was closer, subject to the superimposition of the advance mining influence of the working face and the lateral pressure of the adjacent working face, the roof deformation was very severe and the pressure of the dynamic pressure bearing support increased rapidly, which in turn can very well control the roof deformation. The pressure-monitoring results of the dynamic pressure bearing support were to be found consistent with the variation indicated by the monitoring results of the roof deformation.

\subsubsection{Mine Pressure Behavior Zones of the Reused Entry.} By analyzing the numerical simulation and on-site monitoring results, it can be found that the roof deformation, the stress distribution, and the force applied on the support structure of the reused entry showed obvious zoning features with different distances of the advance working face. According to the variation law of the mine pressure parameters as mentioned above, the deformation and stress distribution of the reused entry in front of the working face can be divided into three zones, as shown in Figure 17.

(1) Stage A. Mine pressure stabilizing zone: the mine pressure stabilizing zone is located beyond approximately $75 \mathrm{~m}$ in front of the working face, where the reused entry was stabilized. In this zone, the entry deformation and the stress distribution of the surrounding rock had the following characteristics: the roof rock was not subject to obvious advance mining influence and the roof-to-floor deformation of the entry was generally small and had no obvious increase. The dynamic pressure bearing support force of the advance working face did not increase significantly but was approximately equal to its initial supporting force. The surrounding rock stress close to the entry remained stable without significant increase or fluctuation. The surface of the entry roof and the solid coal body was relatively flat without obvious rib spalling and roof cracking.

(2) Stage B. Mine pressure gradual change zone: the mine pressure gradual change zone is usually located approximately $25 \sim 75 \mathrm{~m}$ in front of the working face. In this zone, the mining on the working face and the roof movement began to have a certain influence on the entry, but the mining influence was still weak due to its location far away from the working face. Its main features include the following: the roof deformation of the entry began to slowly increase with a small amplitude as the distance from the working face decreased, the dynamic pressure bearing support force of the advance working face began to slowly increase with a small amplitude, and the stress close to the entry began to slowly increase and the amplitude gradually increased as the distance from the working face decreased. Local positions were subject to the rib spalling behavior of a solid coal body with an unobvious effect.

(3) Stage $C$. Mine pressure intensifying zone: the mine pressure intensifying zone is generally located at approximately $0 \sim 25 \mathrm{~m}$ in front of the working face. In this zone, the fracture and movement of the main roof behind the working face would have a significant influence on the entry closer to 


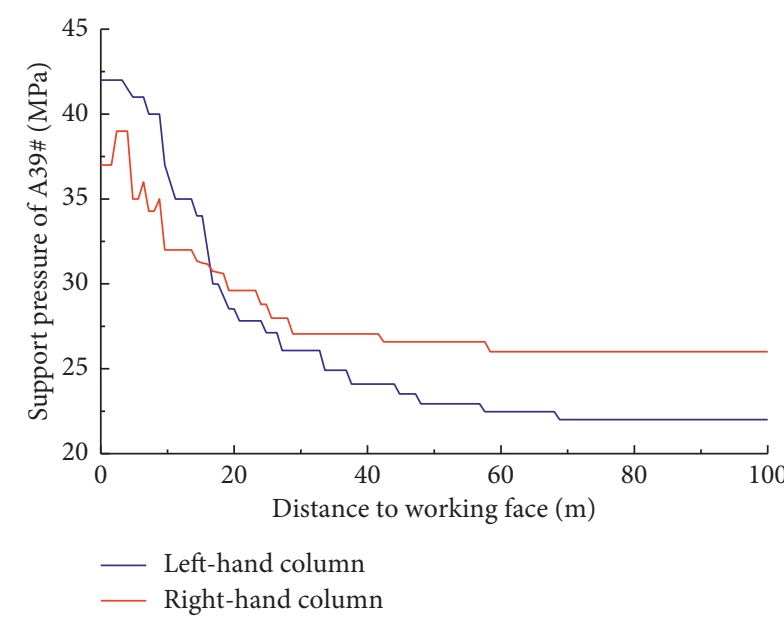

(a)

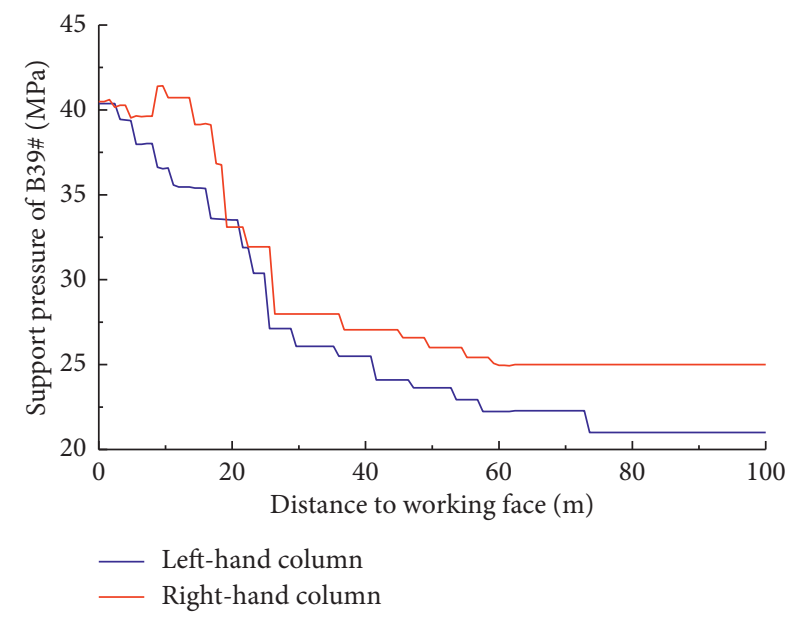

(c)

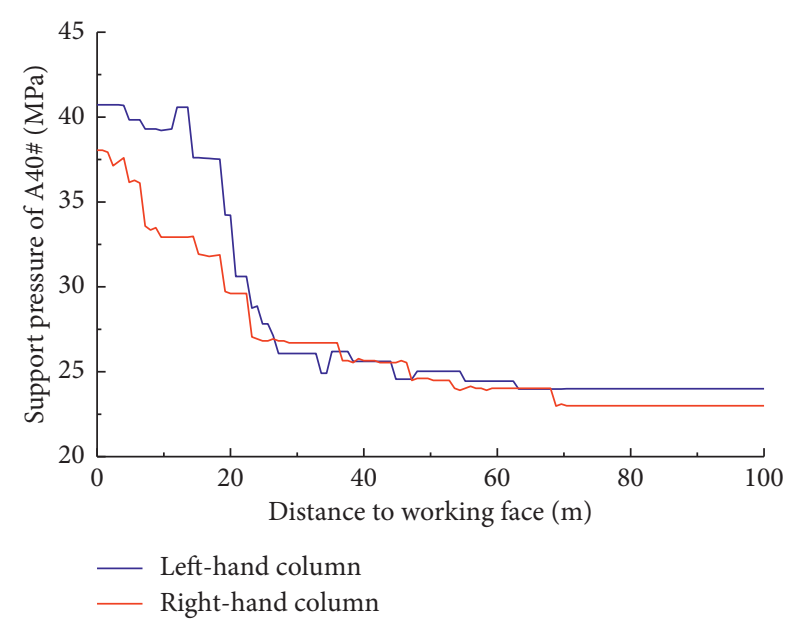

(b)

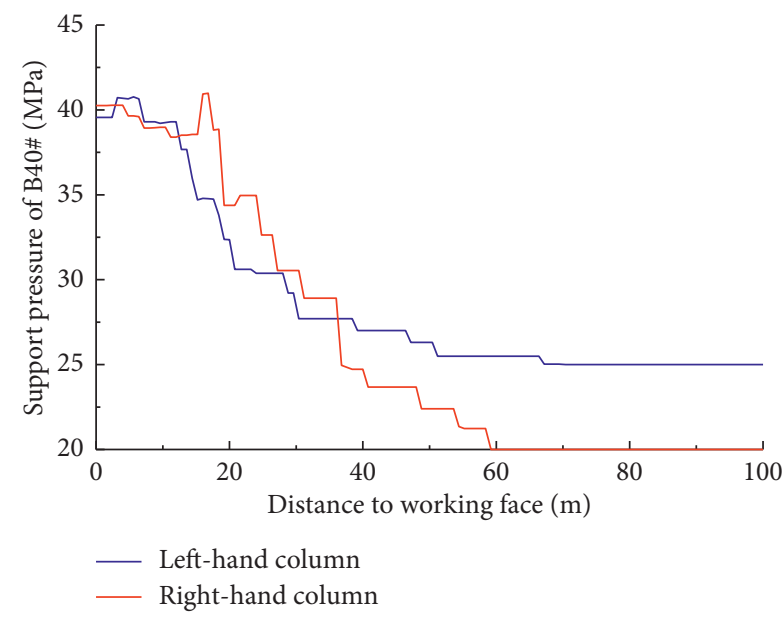

(d)

FIGURE 16: Monitoring results of dynamic pressure bearing supports in front of the working face.
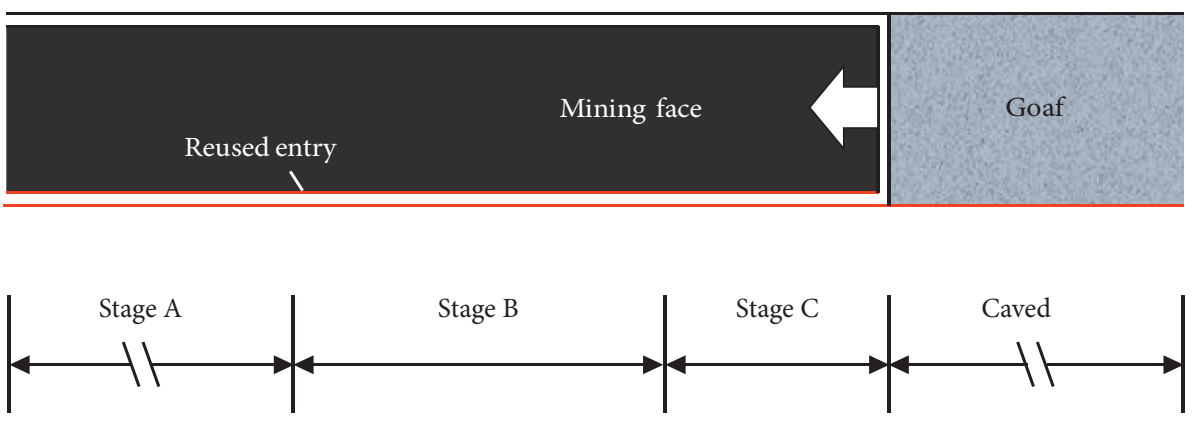

Figure 17: Deformation and stress distribution zones of the reused entry.

the front of the working face. Its main behaviors include the roof deformation sharply increases and the dynamic pressure bearing support force of the advance working face gradually rises. In addition, there was an obvious stress concentration in the coal seam close to the entry; the peak value of the stress concentration occurred approximately $8 \sim 10 \mathrm{~m}$ from the front of the working face. The solid coal body was accompanied by obvious rib spalling and a cracked or damaged roof.

\section{Conclusions}

(1) According to the roof structure and movement characteristics under the mining conditions of noncoal pillar mining with the automatic formation of a roadway, for the working face with one-side mined, the end immediately adjacent to the goaf on the mined working face would result in an "O-Y" failure pattern on the roof, and the triangular fractured rock above 
the reused entry would disappear. This change subjected the reused entry zone to the intense mine pressure behavior from the advance working face such as that occurs in the middle part of the working face, resulting in very significant concentrated stress near the entry in front of the working face, which makes entry maintenance more difficult.

(2) In this work, mine pressure behavior characteristics of the reused entry were analyzed. The findings showed that there was a stress increase zone and a severe deformation zone in a certain range in front of the working face that was subject to the superimposition effect of the lateral pressure of the mined working face and the advance mining pressure on the working face. For the engineering case study of the S12013 working face in the Ningtiaota Coal Mine, the stress increase zone and the severe deformation zone were located in the range of $0-80 \mathrm{~m}$ in front of the working face. Their ranges were approximately $37.5 \%$ larger than those of the ordinary entry on the other side of the mining face. The stress peak of the reused entry in the stress increase zone increased by $34.7 \%$ larger than the ordinary entry on the other side of the mining face. The maximum roof deformation of the reused entry in the severe deformation zone was $105 \mathrm{~mm}$, which was an increase of $94.4 \%$ over that of the ordinary entry on the other side of the mining face.

(3) To improve the stress of the surrounding rock and the deformation control of the reused entry, an advance support method and associated equipment with adaptability to large roof deformation and high support strength was proposed here, which was tailored to provide supplementary support in the stress increase zone and the severe deformation zone of the reused entry and was successfully applied on site. Field application results showed that the final roof deformation with dynamic pressure bearing support can be controlled within 110 130 mm with satisfactory effect.

(4) By analyzing the numerical simulation and on-site monitoring results with different distances from the advance working face, the roof deformation, the stress distribution, and the force applied on the support structure of the reused entry had obvious regular and zoning characteristics. As a result, according to the deformation and stress distribution characteristics of the reused entry in front of the working face, the reused entry was divided into the mine pressure stabilizing zone, the mine pressure changing zone, and the mine pressure intensifying zone. These three zones had different characteristics of deformation and surrounding stress distribution.

\section{Data Availability}

The data used to support the findings of this study are available from the corresponding author upon request.

\section{Conflicts of Interest}

The authors declare that they have no conflicts of interest.

\section{Acknowledgments}

This work was supported by the National Key R\&D Program (no. 2016YFC0600900), National Natural Science Foundation of China (nos. 51904207 and 51674265), China Postdoctoral Science Foundation (no. 2019M661622), and Shandong Provincial Natural Science Foundation, China (no. ZR2017PD011), which are gratefully acknowledged.

\section{References}

[1] D. Mondal, P. N. S. Roy, and P. K. Behera, "Use of correlation fractal dimension signatures for understanding the overlying strata dynamics in longwall coal mines," International Journal of Rock Mechanics and Mining Sciences, vol. 91, pp. 210-221, 2017.

[2] S. S. Peng, F. Du, J. Cheng, and Y. Li, "Automation in U.S. longwall coal mining: a state-of-the-art review," International Journal of Mining Science and Technology, vol. 29, no. 2, pp. 151-159, 2019.

[3] P. Wang, J. Zhao, G. Feng, and Z. Wang, "Improving stress environment in development entries through an alternate longwall mining layout," Arabian Journal of Geosciences, vol. 11, no. 442, 2018.

[4] D. Yin, X. Meng, Z. Zhang, and B. Liu, "Gob-side entry retaining formed by roof cutting without roadside support," International Journal of Oil Gas and Coal Technology, vol. 18, no. 3-4SI, pp. 467-484, 2018.

[5] P. Wang, L. Jiang, P. Zheng, G. Qin, and C. Zhang, "Inducing mode analysis of rock burst in fault-affected zone with a hard-thick stratum occurrence," Environmental Earth Sciences, vol. 78, no. 15, p. 467, 2019.

[6] F. Feng, S. Chen, D. Li, S. Hu, W. Huang, and B. Li, "Analysis of fractures of a hard rock specimen via unloading of central hole with different sectional shapes," Energy Science \& Engineering, vol. 7, no. 6, 2019.

[7] D. Mondal and P. N. S. Roy, "Fractal and seismic b-value study during dynamic roof displacements (roof fall and surface blasting) for enhancing safety in the longwall coal mines," Engineering Geology, vol. 253, pp. 184-204, 2019.

[8] Y. Li, S. Zhang, and X. Zhang, "Classification and fractal characteristics of coal rock fragments under uniaxial cyclic loading conditions," Arabian Journal of Geosciences, vol. 11, no. 9, 2018.

[9] P. Wang, H. Jia, and P. Zheng, "Sensitivity analysis of bursting liability for different coal-rock combinations based on their inhomogeneous characteristics," Geomatics, Natural Hazards and Risk, vol. 11, no. 1, 2020.

[10] Y. Wang, Y. Gao, E. Wang, M. He, and J. Yang, "Roof deformation characteristics and preventive techniques using a novel non-pillar mining method of gob-side entry retaining by roof cutting," Energies, vol. 11, no. 3, p. 627, 2018.

[11] Y. Li, E. Zhu, K. Zhang, M. Li, J. Wang, and C. Li, "Longwall mining under gateroads and gobs of abandoned small mine," International Journal of Mining Science and Technology, vol. 27, no. 1, pp. 145-152, 2017.

[12] S. Zhang, Y. Li, B. Shen, X. Sun, and L. Gao, "Effective evaluation of pressure relief drilling for reducing rock bursts and its application in underground coal mines," International 
Journal of Rock Mechanics and Mining Sciences, vol. 114, pp. 7-16, 2019.

[13] Z. Li, Z. Tao, Z. Meng, and M. He, "Longwall mining method with roof-cutting unloading and numerical investigation of ground pressure and roof stability," Arabian Journal of Geosciences, vol. 11, p. 69722, 2018.

[14] X. Yang, C. Hu, M. He et al., "Study on presplitting blasting the roof strata of adjacent roadway to control roadway deformation," Shock and Vibration, vol. 2019, Article ID 3174898, 16 pages, 2019.

[15] G. Feng, Y. Kang, Z.-d. Sun, X.-c. Wang, and Y.-q. Hu, "Effects of supercritical $\mathrm{CO}_{2}$ adsorption on the mechanical characteristics and failure mechanisms of shale," Energy, vol. 173, pp. 870-882, 2019.

[16] Y. Wang, M. He, J. Yang et al., "Case study on pressure-relief mining technology without advance tunneling and coal pillars in longwall mining," Tunnelling and Underground Space Technology, vol. 97, Article ID 103236, 2020.

[17] D. Qian, N. Zhang, H. Shimada, C. Wang, T. Sasaoka, and N. Zhang, "Stability of goaf-side entry driving in 800-m-deep island longwall coal face in underground coal mine," Arabian Journal of Geosciences, vol. 9, no. 821, 2016.

[18] C.-1. Han, N. Zhang, Z. Ran, R. Gao, and H.-q. Yang, "Superposed disturbance mechanism of sequential overlying strata collapse for gob-side entry retaining and corresponding control strategies," Journal of Central South University, vol. 25, no. 9, pp. 2258-2271, 2018.

[19] M. Shabanimashcool and C. C. Li, "A numerical study of stress changes in barrier pillars and a border area in a longwall coal mine," International Journal of Coal Geology, vol. 106, pp. 39-47, 2013.

[20] B. Huang, S. Chen, and X. Zhao, "Hydraulic fracturing stress transfer methods to control the strong strata behaviours in gob-side gateroads of longwall mines," Arabian Journal of Geosciences, vol. 10, Article ID 23611, 2017.

[21] X. Yang, E. Wang, X. Ma, G. Zhang, R. Huang, and H. Lou, “A case study on optimization and control techniques for entry stability in non-pillar longwall mining," Energies, vol. 12, p. 3913, 2019.

[22] J. Kan, N. Zhang, J. Wu, and $\mathrm{H}$. Wu, "Effect of main roofs fracture position on the secondary gob-side entry retaining stability," Disaster Advances, vol. 6, no. 5, pp. 189-199, 2013.

[23] H. Yin, L. Lefticariu, J. Wei, J. Guo, Z. Li, and Y. Guan, "In situ dynamic monitoring of stress revolution with time and space under coal seam floor during longwall mining," Environmental Earth Sciences, vol. 75, p. 124918, 2016.

[24] N. Hosseini, K. Oraee, K. Shahriar, and K. Goshtasbi, "Passive seismic velocity tomography on longwall mining panel based on simultaneous iterative reconstructive technique (sirt)," Journal of Central South University, vol. 19, no. 8, pp. 22972306, 2012.

[25] J. Lu and G. Hasenfus, "Challenges of mining the first righthanded longwall panel in a new reserve block in pittsburgh seam," International Journal of Mining Science and Technology, vol. 29, no. 1, pp. 145-149, 2019.

[26] F. Wang, Q. Ma, G. Li, C. Wu, and G. Guo, "Overlying strata movement laws induced by longwall mining of deep buried coal seam with superhigh-water material backfilling technology," Advances in Civil Engineering, vol. 2018, Article ID 4306239, 10 pages, 2018.

[27] S. Mahdevari, K. Shahriar, M. Sharifzadeh, and D. D. Tannant, "Assessment of failure mechanisms in deep longwall faces based on mining-induced seismicity," Arabian Journal of Geosciences, vol. 9, Article ID 70918, 2016.
[28] J.-b. Bai, W.-l. Shen, G.-l. Guo, X.-y. Wang, and Y. Yu, "Roof deformation, failure characteristics, and preventive techniques of gob-side entry driving heading adjacent to the advancing working face," Rock Mechanics and Rock Engineering, vol. 48, no. 6, pp. 2447-2458, 2015.

[29] H. Wang, Y. Jiang, Y. Zhao, J. Zhu, and S. Liu, "Numerical investigation of the dynamic mechanical state of a coal pillar during longwall mining panel extraction," Rock Mechanics and Rock Engineering, vol. 46, no. 5, pp. 1211-1221, 2013.

[30] H. Kang, J. Lou, F. Gao, J. Yang, and J. Li, "A physical and numerical investigation of sudden massive roof collapse during longwall coal retreat mining," International Journal of Coal Geology, vol. 188, pp. 25-36, 2018.

[31] P. Konicek and J. Schreiber, "Heavy rockbursts due to longwall mining near protective pillars: a case study," International Journal of Mining Science and Technology, vol. 28, no. 5, pp. 799-805, 2018. 